\title{
ROBERT E. HOWARD: LA ESPADA SALVAJE DE LA IDEOLOGÍA
}

\section{ROBERT E. HOWARD: THE SAVAGE SWORD OF IDEOLOGY}

\author{
Luis Felip López-Espinosa ${ }^{1}$ \\ Universidad de Málaga
}

Recibido: 9/ 7/ 16

Aceptado: 29/ 1/ 17

Resumen: El bárbaro de Robert E. Howard es un héroe crítico. De acuerdo con los intérpretes, Conan no actúa legitimado por el Destino, como viene siendo habitual en el género de «espada y brujería». El bárbaro está ligado a una naturaleza que disuelve las ficciones imaginarias de la civilización. Sin embargo, el bárbaro como crítico de la cultura no tiene nada en común con el desdén fascista por la decadencia burguesa; está más relacionado con la "violencia divina» benjaminiana. En conclusión, identificaremos la violencia utópica del bárbaro, cuyo poder carece de toda legitimación ideológica, como el núcleo de toda democracia real y radical.

Palabras clave: Robert E. Howard; Walter Benjamin; ideología; violencia divina; democracia.

\begin{abstract}
Robert E. Howard's barbarian is a critical hero. According to the interpreters, Conan doesn't acts legitimized by the Destiny, as is being usual in the genre of sword-and-sorcery. The barbarian is linked to a nature which dilutes the imaginary fictions of civilization. However, the barbarian as a culture critic does not have nothing in common with the fascist desdain for the bourgeois decadency; is more linked with the benjaminian "divine violence». In conclusion, we'll identify the utopic violence of the barbarian, whose power is deprived of any ideological legitimation, as the kernel of real and radical democracy.
\end{abstract}

Keywords: Robert E. Howard; Walter Benjamin; Ideology; Divine Violence; democracy

1. Colaborador honorario en el Departamento de Filosofía de la Universidad de Málaga. Dr. en Filosofía por la UNED, sus líneas principales de trabajo son el concepto de ideología, la filosofía marxista (con especial atención a la perspectiva althusseriana) y la teoría psicoanalítica tal como se encuentra formulada por Jacques Lacan y desarrollada en sus aplicaciones filosóficas y políticas por parte de la Escuela de Eslovenia. Publicaciones recientes: «Il n'y a pas de grand Autre: el materialismo teológico de Pascal», en Daimón. Revista Internacional de Filosofía, n 51 (2010); «El concepto de ideología en el Marx maduro», en Isegoría, Nº 50 (2014). 


\section{El «existencialismo» de Conan como crítica de la ideología}

En su breve artículo titulado «Conan The Existential», Charles Hoffman reivindica la actualidad de la obra de Robert E. Howard por su vinculación, aunque no expresa ni consciente, con una de las corrientes filosóficas más importantes del siglo XX: el existencialismo. ${ }^{2}$ La obra de Howard no sería una reactualización del mito, ni una saga más de «ficción histórica» inspirada en un pasado remoto e idealizado, con toques de fantasía heroica. Como sostiene Hoffman, se trata de una obra existencialista en lo filosófico y arraigada fuertemente, por tanto, en la constelación filosófica e ideológica de su momento histórico, el turbulento siglo XX.

Muy sucintamente, y reduciendo el concepto de manera un tanto simplista, Hoffman identifica el existencialismo de Howard en torno a la tesis sartriana elemental de "la existencia precede a la esencia», el «absurdo de la existencia humana» en Camus, y la negación del concepto de «naturaleza humana». ${ }^{3}$ Aunque la identificación con una escuela filosófica de pensamiento en su artículo es algo débil, sin dar una definición precisa del término «existencialismo» (más allá de la impresión de un «clima intelectual»), sin profundización en la obra de Sartre o Camus ni de sus precedentes (Kierkegaard, Pascal, etc.) y sin el recurso a un aparato crítico que aporte algo más de rigor académico, debemos convenir con Hoffman en que las narraciones de Robert E. Howard destacan como una obra de su tiempo, y lo interesante del artículo reside en los argumentos aportados que abren la puerta a una interpretación más ambiciosa desde un punto de vista filosófico.

La identificación de Robert E. Howard como un «existencialista inconsciente» en el breve ensayo de Charles Hoffman se centra en un aspecto crucial de su narrativa, que la distinguiría de la obra de otros célebres autores de fantasía heroica como Tolkien o Moorcock: la ausencia de un llamado al Destino del héroe. Este es un elemento central, traicionado por epígonos como Sprague de Camp y Lin Carter (continuadores de la saga de Conan tras la muerte de Howard), y olvidado por los sucesores en el género de «espada y brujería»:

Todos los sucesores de Howard en el género de espada y brujería parecen insensibles al existencialismo (...); la mayoría de sus series con crónicas del héroe que cumple con su "noble destino". En cada una de las historias de Howard, Conan crea y soporta su propio destino. Cuando Conan se convierte en rey, no está realizando un papel predeterminado por el destino; al contrario, él aprovecha la oportunidad para autoproclamarse rey. ${ }^{4}$

2. Hoffman, Ch: «Conan The Existential», en Herron, D. (ed): The barbaric Triumph, Maryland: Wildside Press, 2004, pp. 5-10.

3. Ibídem, pp. 6-7.

4. «All of Howard's successors in the genre of Sword-and-Sorcery seem untouched by exis-

Thémata. Revista de Filosofía $\mathrm{N}^{\circ} 55$ (2017) pp.: 267-286. 
El carácter propio y la profundidad del mundo creado por Howard se comprenden mejor por contraste con la obra de otro referente de la literatura de fantasía: Tolkien. En Tolkien es evidente el aura de mistificación que envuelve todo el relato, con la montaña (en El señor de los anillos o en El Hobbit) como telos o fin hacia el cual se dirige linealmente la trama. Quizás por eso el prototipo del mago tolkieniano, Gandalf, es aquel que conoce dicho Destino o finalidad. Operando mediante engaños, poniendo en peligro a Bilbo y a Frodo, Gandalf les hace cumplir con una oscura finalidad histórica: robar el perdido anillo de poder de Sauron, atesorado por Gollum, y hacerlo fundir en Mordor. Los más idóneos para semejantes aventuras son los hobbits o medianos, una raza sencilla, hogareña, ingenua y de aspiraciones modestas (menos susceptibles que los humanos al pecado o a la corrupción).

¿Y no es esta llamada a un crucial Destino (que da nombre al mismísimo monte donde Frodo cumple su misión en El Señor de los Anillos) lo más característico de la interpelación ideológica, tal como la planteara Louis Althusser y la desarrollaran Slavoj Žižek y los autores de la escuela eslovena? La ideologia interpela a los individuos como sujetos, y lo hace mediante la representación imaginaria de una completud, proyectada sobre las carencias del ser materialmente incompleto e insuficiente. Lo que un sujeto es, y lo que debe ser, se hallan codificados en la forma de un Destino socialmente necesario, merecedor de nuestra sumisión e incluso de nuestra aceptación en forma de «amor fati» pseudonietzscheano. Mladen Dolar describe este proceso como la introyección de una contingencia externa, que por medio de un cambio meramente formal conduce a una elección forzada, allí donde lo dado es percibido como el objeto de elección del propio sujeto. ${ }^{5}$

¿No sucede así cuando Gandalf convence a Bilbo de que le siga en su aventura? Bilbo es tajante en su negativa ( $i$ No queremos aventuras aquí, gracias!»). ${ }^{6} \mathrm{Y}$ sin embargo, Gandalf no duda en llenar de enanos la casa de Bilbo, la tarde del día siguiente. La compañía de los enanos y las canciones sobre mazmorras, oro y aventuras, despiertan el interés de Bilbo. Sin embargo, tras la fiesta, «ya no estaba tan seguro de que fuese a

tentialism (...); most of their series are chronicles of the hero fulfilling his «noble destiny». In each of Howard's stories, Conan creates and carries out his own destiny. When Conan becomes king, he is not acting out a role already preordained by fate; rather, he seizes the opportinuty to make himself a king» (Ibidem, p. 8, la traducción es mía).

5. Dolar, M.: «Beyond interpellation», Qui Parle, 6:2, 1993, p. 82.

6. Tolkien, J.R.R.: El hobbit. Barcelona: Círculo de Lectores, 1988, pp. 11-12.

Thémata. Revista de Filosofía N55 (2017) pp.: 267-286. 
hacer algún viaje por la mañana». ${ }^{7}$ La decisión de partir se toma como un hecho ya consumado: al amanecer, los enanos se han marchado dejándole una nota, que Bilbo no halla hasta que Gandalf se la hace leer, apremiándole a que se reuna con el grupo de aventureros. Así, del modo más absurdo, Bilbo se lanza a la aventura:

Hasta el final de sus días Bilbo no alcanzó a recordar cómo se encontró fuera, sin sombrero, bastón, o dinero, o cualquiera de las cosas que acostumbraba a llevar cuando salía, dejando el segundo desayuno a medio terminar, casi sin lavarse la cara, y poniendo las llaves en manos de Gandalf... ${ }^{8}$

El proceso de «conversión» ideológica supone la confirmación de un hecho consumado, apoyado en la autoridad externa del mago (y en cierto sentido, facilitado también por el mito familiar, la ascendencia de una estirpe de aventureros). La paradoja del relato reside en cómo la aventura se convierte en una búsqueda de la propia identidad a partir del hecho traumático de que, una vez que se inicia la búsqueda, algo de esa identidad preexistente se pierde. En otras palabras: sin la ruptura que la elección forzada supone en la cotidianeidad homeostática de un sujeto, la propia aventura sería innecesaria... pues el sujeto no habría tenido necesidad de buscarse a sí mismo a través de la historia.

Al final de $\mathrm{El} \mathrm{Hobbit,} \mathrm{Gandalf} \mathrm{muestra} \mathrm{la} \mathrm{verdadera} \mathrm{lógica} \mathrm{del} \mathrm{pro-}$ ceso de interpelación ideológica, donde con total descaro el mandato ideológico resulta ser la condición de posibilidad del acto individual de un sujeto, y no al contrario:

¿No dejarás de creer en las profecías solo porque ayudaste a que se cumplieran? No supondrás, ¿verdad?, que todas tus aventuras y escapadas fueron producto de la mera suerte, para tu beneficio exclusivo. Te considero una gran persona, señor Bolsón, y te aprecio mucho; pero en última instancia, jeres solo un simple individuo en un mundo enorme $!^{9}$

La preeminencia del mito, la sumisión del individuo a la colectividad, y el papel preeminente del mago como conocedor de un destino, se hallan diametralmente opuestos al «vulgar» materialismo de Conan, individualista y desmitificador. Conan es presentado, en su primera aparición en el relato «The Phoenix on the Sword» (publicado en el número de

7. Ibidem, p. 28.

8. Ibidem, p. 30.

9. Ibidem, p. 228.

Thémata. Revista de Filosofía N55 (2017) pp.: 267-286. 
diciembre de 1932 de Weird Tales), como un antihéroe disolvente o como un héroe plebeyo:

Allí llegó Conan, el cimmerio, con su pelo negro, los ojos sombríos, espada en mano, un ladrón, un saqueador, un asesino, de gigantescas melancolías y gigantescas alegrías, para pisotear con sus sandalias los tronos enjoyados de la tierra. ${ }^{10}$

Las líneas que abren el relato no constituyen una profecía, sino una crónica (se citan unas imaginarias «Crónicas Nemedias»). Por ese motivo, la narración se mantiene en todo momento enmarcada en una crónica ficticia, pero desde un supuesto puramente materialista y sin anticipar ninguna determinación histórica. De una manera brutal, el universo del héroe en Howard se rige por la contingencia absoluta de un proceso sin Sujeto ni fin(es). ${ }^{11} \mathrm{El}$ antiheroico Conan pasa por su vida a través de toda suerte de oficios de mala reputación (pirata, ladrón, soldado profesional, general mercenario, forajido...) guiado tan solo por «primarias» necesidades materiales. De ahí que su auto-coronación como rey de Aquilonia (en un gesto napoleónico) esté desprovista del aura de una profecía, de la predicción de una necesidad histórica. Conan, sin más autoridad que la que le dan las circunstancias concretas, recoge la corona del cadáver del tirano Numénides, a quien acaba de dar muerte. ${ }^{12}$ Y como experimentará a partir de entonces, ninguna sublime transformación enderezará su vida de aventurero y buscavidas, pues como acertó Jacques Lacan, el loco no es solamente el mendigo que cree ser un rey, sino también el rey que cree serlo. La crítica howardiana a la monarquía se basa, por consiguiente, no en la negación del estatus trascendente de la misma, sino en la afirmación de su carácter mundano: no existe diferencia alguna entre ser un rey o ser un bárbaro, pues un bárbaro puede ocupar el trono como el mejor de los monarcas (asumiendo precisamente que reinar no consiste en la multitud de sofisticadas artes cortesanas, las cuales corrompen al monarca y llevan

10. «Hither came Conan, the Cimmerian, black-haired, sullen-eyed, sword in hand, a thief, a reaver, a slayer, with gigantic melancholies and gigantic mirth, to tread the jeweled thrones of the Earth under his sandalled feet» (Howard, R. E.: "The Phoenix on the Sword», en The Coming of Conan the Cimmerian, New York: Del Rey, 2003, p. 7, la traducción es mía.)

11. Althusser, L.: «Remarque sur une catégorie: "Procés sans Sujet ni Fin(s)"», en Réponse a John Lewis, Paris: Maspero, 1973, pp. 69-76.

12. La historia, mencionada en "The Phoenix on the Sword», es narrada con pormenores en Sprague de Camp, L. y Carter, L.: Conan the Liberator, New York: Tor, 2002, pp. 153-294.

Thémata. Revista de Filosofía N55 (2017) pp.: 267-286. 
al reino a la decadencia, sino en el ejercicio de la política como aventurerismo, arribismo y violencia).

La postura del héroe resultaría en una ética que, conocedora el papel eficaz de la ideología, sin embargo la rechaza, en una empresa de desencantamiento del mundo a través del gobierno por la espada (el althusseriano Aparato Represivo de Estado) y no por la ideología. El primer relato de Conan, "El fénix en la espada", era una reescritura de un relato de Kull que la revista Weird Tales rechazó (alegando precisamente a que la falta de elementos fantásticos sería mal recibida por los lectores), con un título muy significativo: «By this axe I rule!», ${ }^{13}$ "Por este hacha gobierno». En este punto, cabría calificar la política de Howard como un antimaquiavelismo desde un materialismo "vulgar», y sin embargo utópico.

Antimaquiavelismo, porque $E l$ príncipe (dejando de lado por ahora el Maquiavelo alternativo de los Discursos sobre la primera década de Tito Livio) argumenta la hibridación de violencia e ideología como claves inseparables para el gobierno, argumentando la imposibilidad de mantener el gobierno solo mediante el ejercicio del poder del Estado.

Materialismo vulgar e ingenuo, porque el héroe de Howard rechaza este papel de la ideología y remite en última instancia a la violencia como fundamento real de todo poder legítimo. Y sin embargo utópico, porque persigue en último término un ideal emancipatorio. El bárbaro de Howard busca el instrumento de dicha emancipación en una forma muy concreta de violencia, una violencia por medio de la cual se destituye aquella ficción imaginaria o ideológica que acompaña a las sociedades civilizadas, desigualitarias y contradictorias.

\section{Conan, el bárbaro emancipador}

Steven R. Trout ha escrito acerca de las relaciones de Robert E. Howard con el mito americano de la frontera. ${ }^{14} \mathrm{Y}$ es que resulta muy complicado entender el personaje del bárbaro, y más aún la propia cultura estadounidense, sin referirse a la historia de violencia, conquista y colonización que aún se halla relativamente reciente en la historia de ese país.

Trout nos remite en su artículo a la obra de Slotkin. En Regeneration Through Violence,$^{15}$ Richard Slotkin traza la historia del «mito de la

13. Howard, R. E.: «By this axe I rule!», en The best of Robert E. Howard, vol. 2, New York: Del Rey, 2007, pp. 1-17.

14. Trout, S. R.: «Heritage of Steel: Howard and the Frontier Myth», en Herron, D. (ed): The barbaric Triumph, O. Cit., pp. 59-78.

15. Slotkin,R.: Regeneration through violence. The Mythology of the American Frontier, 1600-

Thémata. Revista de Filosofía ํ55 (2017) pp.: 267-286. 
frontera» como mito nacional en la cultura norteamericana. La mitología americana no la construyeron los padres fundadores, intelectuales ilustrados del XVIII, sino que se constituyó sobre las actitudes, la psicología y los devenires de la dura vida de los exploradores, colonos, misioneros... y de su enfrentamiento con la naturaleza y con los nativos americanos. ${ }^{16}$ Especialmente en la época de las guerras anticoloniales indígenas (o "guerras indias»), la cultura norteamericana se construyó sobre una experiencia de la civilización confrontada a la barbarie. Al mismo tiempo, en ese complejo sustrato histórico surgirá la fascinación norteamericana por figuras que mezclan civilización y barbarie, como el explorador Daniel Boone, el cual encarna al prototipo de lo que va a ser en adelante el héroe americano: «un héroe americano es el amante del espíritu de las tierras salvajes, y sus actos de amor y de sagrada afirmación son actos de violencia contra este espíritu y sus avatares». ${ }^{17}$ Esta misma identificación del héroe con la naturaleza la hallamos en un pasaje de El coloso negro: "No era un mero salvaje; era parte de lo salvaje, era uno con los indomables elementos de la vida». ${ }^{18}$

La relación con el barbarismo toma entonces para el colono un doble carácter, de fascinación y de represión. Por un lado, el hombre blanco, formado en la cultura puritana, experimenta los dos mundos como antagónicos, como estructuras simbólicamente contrapuestas: «Para cada institución puritana, para cada práctica y para cada teoría moral, creencia y ritual, existía una antítesis y una contraparte india. Estas analogías nunca fueron ignoradas por los puritanos, que veían en ellas metáforas de la voluntad de Dios». ${ }^{19}$ Por otra parte, subyace una atracción hacia lo salvaje: «Los blancos apreciaban y envidiaban lo que para ellos era la naturalidad de los indios ante la vida y la sexualidad.» ${ }^{20}$

El conflicto generado por esta ambivalencia es característico del género western. En el documental The pervert's guide to Ideology (Sophie

1860, Norman: University of Oklahoma Press, 2000.

16. Ibidem, p. 4.

17. «...an American hero is the lover of the spirit of the wilderness, and his acts of love and sacred affirmation are acts of violence against that spirit and her avatars» (Ibidem, p. 22, la traducción es mía).

18. «He was not merely a wild man; he was part of the wild, one with the untamable elements of life» (Howard, R.E.: «Black Colossus», en The Coming of Conan the Cimmerian, O. Cit., p. 172, la traducción es mía).

19. «For every Puritan institution, moral theory and practice, belief and ritual there existed an anthitetical Indian counterpart. Such analogies were never lost on the Puritans, who saw in them metaphors of God's will» (Slotkin, R.: O. Cit., p. 57, la traducción es mía).

20. «The whites appreciated and envied what they took to be the Indian's ease of life and sexuality" (Ibídem, p. 26, la traducción es mía).

Thémata. Revista de Filosofía №55 (2017) pp.: 267-286. 
Fiennes, 2012), Slavoj Žižek se detiene a analizar el clásico western Centauros del desierto (The Searchers, John Ford, 1956) para analizar cómo el héroe que dedica todos sus esfuerzos en rescatar a la mujer presa de la tribu india consigue por fin dar con su pista, solo para descubrir con escándalo que ella no desea ser rescatada. Este argumento es el mismo en Taxi Driver (Martin Scorsese, 1977), donde el protagonista se ve a sí mismo como el héroe que debe liberar a una prostituta. En ambos casos, los protagonistas se hallan sobreidentificados con un destino heróico que supone doblegar a las fuerzas del barbarismo; en ambos casos, el único modo para llevarlo a cabo es por medio de la barbarie y la violencia. En Taxi Driver es muy revelador el corte de pelo a lo mohicano de Travis para marchar a la batalla.

Siguiendo a Žižek, la única solución real al problema que los dos filmes plantean hubiera sido la que escenifica el protagonista de Taxi Driver al final de la película, disparándose simbólicamente con el dedo en la sien: en otras palabras, ejercer la violencia sobre uno mismo. En efecto, Travis debía disparar contra aquello que más cuesta ceder: contra las certezas ideológicas que conforman su propia subjetividad, y que el acto irreflexivo de violencia trata realmente de salvar. Para Žižek, los estallidos de violencia no constituyen el efecto de una firme convicción, sino más bien el síntoma de una flaqueza: son un modo falso de lidiar con una contradicción interna; constituyen una reacción desmedida cuando nuestras certezas ideológicas se ven amenazadas.

En Sobre el concepto de historia, Walter Benjamin presenta su célebre afirmación «no hay documento de cultura que no sea al mismo tiempo de barbarie». ${ }^{21}$ La historia de las sociedades contradictorias avanza por medio del empoderamiento de unos y de la servidumbre de la mayoría; lo que entendemos como tradición es el proceso de transmisión de ese legado de los vencedores. Por ese motivo, tras los «bienes culturales», que son la materialización de esa hegemonía, subyace una historia "anónima», una «tradición de los oprimidos». ${ }^{22}$ La propuesta de Benjamin es por tanto que el materialista histórico no empatice con los vencedores, que sea capaz de distanciarse de este proceso de transmisión; esta argumentación es la que le lleva a la también célebre sentencia acerca del materialista histórico que "considera como su tarea cepillar la historia a contrapelo». ${ }^{23}$

Es en este sentido preciso en que una teoría crítica debe abrazar un barbarismo emancipador, ante la certidumbre de que un proyecto civi-

21. Benjamin, W.: «Sobre el concepto de historia», en Obras Completas, Libro I/vol 2, Madrid: Abada, 2008, p. 309.

22. Ibidem.

23. Ibídem.

Thémata. Revista de Filosofía ํ55 (2017) pp.: 267-286. 
lizatorio que no reconozca ese elemento disolvente se convertirá también él mismo en una fuente de barbarie. Este fue el descubrimiento que hizo Marx. De justificar en cierto modo al capitalismo porque disuelve las abigarradas relaciones feudales y dispone el terreno para la emancipación socialista, ${ }^{24}$ Marx pasó a aceptar que el proceso histórico no debía necesariamente atravesar todos los estadios de desarrollo de una manera mecánica y disolvente de las instituciones «precapitalistas» (esta perspectiva se encuentra en sus reflexiones más tardías referidas al papel de la comunidad rural en Rusia). ${ }^{25}$ Toda la polémica, de consecuencias cruciales, que más tarde dividió la II Internacional y que enfrentó a Lenin con Kautsky, tenía que ver con este giro teórico desde la visión lineal de la historia a la aceptación de múltiples vías hacia el socialismo. De este modo, Lenin confrontaría con el mecanicismo de la socialdemocracia alemana, que veía en el desarrollo de las fuerzas productivas el camino seguro y pavimentado al socialismo, y "accionó el freno de mano» en un sentido benjaminiano, aunque no se dieran las condiciones objetivas.

\section{Conan, el destructor benjaminiano}

En su conferencia «A Positive Concept of Barbarism», ${ }^{26}$ Sami Khatib comenta una carta de Robert E. Howard dirigida a Lovecraft en diciembre de 1935.

Tu amigo Mussolini es un ejemplo sorprendentemente actual. En aquel discurso que escuché, él hablaba libremente de la expansión de la civilización. De vez en cuando anunciaba: «iLa espada y la civilización deben ir de la mano!» «iAllí donde la bandera italiana ondee, lo hará como un símbolo de la civilización!» (...) Las naciones civilizadas nunca, nunca tienen motivos egoístas para asesinar, violar y saquear; sólo los horribles bárbaros los tienen. ${ }^{27}$

24. Marx, K. y Engels, F.: «Manifiesto del Partido Comunista», en Obras Escogidas, 1, Madrid: Akal, 1975, p. 24.

25. K. Marx, «Carta a Vera Zassulitch, 8 de marzo de 1881», en Marx, K. y Engels, F.: Cartas sobre El Capital, Barcelona: Laia, 1974, pp 234-235.

26. Khatib, S.: «A Positive Concept of Barbarism. Benjamin and Consequences», charla dentro del ciclo "Constellations of Contemporary Thought» en el Multimedia institute klub MaMa, Zagreb, Croatia, 27 de febrero de 2015, https://www.youtube.com/watch?v=VGQxP5r9htQ [Consultado: 3/07/2016]. Una versión del texto se publicará próximamente en forma de artículo bajo el título "The Poverty of Theory: Benjamin and the Consequences», en la revista Historical Materialism: Research in Critical Marxist Theory. Citado con permiso del autor.

27. "Your friend Mussolini is a striking modern-day example. In that speech of his I heard translated he spoke feelingly of the expansion of civilization. From time to time he has announced: "The sword and civilization go hand in hand!" "Wherever the italian flag waves it

Thémata. Revista de Filosofía N55 (2017) pp.: 267-286. 
Como bien señala Khatib, en la literatura de los años treinta el término «barbarie» no tenía siempre un sentido peyorativo ni estaba asociado únicamente al fascismo. En la carta, Howard sitúa claramente a los bárbaros entre los oprimidos, comprendiendo perfectamente cómo todo imperialismo y toda dictadura comienza identificando al otro como el sub-humano, basando esta atribución en la raza y la cultura. Por eso, contra las intepretaciones apresuradas, que pudieran ver alguna forma de crítica fascista a la decadencia burguesa en la actitud de Conan ante los cínicos y débiles hombres civilizados, conviene recordar que lo que Conan desprecia no son precisamente los placeres decadentes de la ciudad. En el fondo, pese a las apariencias, la ciudad presenta un medio idóneo donde las habilidades del bárbaro lo hacen más adaptado que cualquier hombre civilizado.

Lo que diferencia al civilizado del bárbaro es que el primero precisa de una justificación de la violencia por encima del mero interés. La violencia, en las culturas civilizadas, es presentada como un mal necesario que conviene ocultar; por eso precisamente Conan se gana el sustento en múltiples ocasiones como mercenario de algún reino civilizado. En las culturas civilizadas, la fuerza es un medio y nunca un fin en sí mismo; pero esta instrumentalización de la violencia conlleva una violencia "estructural» o soterrada. Precisamente contra esta violencia soterrada, el acto barbárico de voluntad es utópico, disolvente y subversivo.

El héroe howardiano es un «nihilista activo» ${ }^{28}$ en el sentido nietzscheano. Esta figura es característica de personajes literarios de la cultura popular, como los detectives de Dashiell Hammett o Raymond Chandler. Conan se presenta como un explorador y un aventurero. Su drama es el del individuo que, enfrentándose a sus pasiones humanas y naturales (la superstición característica de los pueblos salvajes respecto de los seres sobrenaturales y la hechicería; el deseo sexual, como en las novelas de serie negra donde el detective de turno renuncia al amor) se sobrepone a sus pasiones y se sirve de una violencia estéril y distante para llevar a cabo la gesta de la destrucción de lo viejo.

Este nihilismo activo está muy presente en el texto «El carácter destructivo» de Walter Benjamin, donde se invoca la posición ética de un desapasionado desbrozador de sendas, de un explorador de posibilidades históricas: «El carácter destructivo solo conoce una consigna: hacer sitio;

will be as a symbol of civilization!” (...) Civilized nations never, never have selfish motives for butchering, raping and looting; only horrid barbarians have those» (Herron, D.: «The Barbaric Triumph", en The Barbaric Triumph, O. Cit., p. 175, la traducción es mía).

28. Nietzsche, F.: El nihilismo: escritos póstumos, Barcelona: Península, 2002, p. 64.

Thémata. Revista de Filosofía N55 (2017) pp.: 267-286. 
solo una actividad: despejar. Su necesidad de aire fresco y espacio libre es más fuerte que todo odio.» ${ }^{29}$

Walter Benjamin define el carácter destructivo como juvenil y capaz de grandes alegrías. "A esta imagen apolínea del destructivo nos lleva por de pronto el atisbo de lo muchísimo que se simplifica el mundo si se comprueba hasta qué punto merece la pena su destrucción». ${ }^{30}$ Definido por la alegría espinosista de incrementar la potencia de obrar, sin odio ni temor, pareciera la única vía moderna para la aplicación de las intuiciones de una ética confrontada con la realidad del mundo contemporáneo, un mundo que debe ser enfrentado desde un punto de vista minimalista, reduccionista y revolucionario. Como tal ética revolucionaria, Benjamin define el carácter destructivo como un proceder sin telos, sin proyecto subjetivo:

Tiene pocas necesidades y la mínima sería saber qué es lo que va a ocupar el lugar de lo destruido. Por de pronto, por lo menos por un instante, el espacio vacío, el sitio donde estuvo la cosa que ha vivido el sacrificio. ${ }^{31}$

El bárbaro personifica la fuerza de lo salvaje, de lo que proviene extramuros de la civilización. Es la concreción por antonomasia de una ética desapasionada, que ha de aplicar en la praxis la crítica del estado de cosas existente. Como ha afirmado Žižek, el drama de nuestra civilización capitalista occidental es que no podemos representarnos su alteridad: resulta más fácil para nosotros imaginar el fin del mundo y la destrucción de toda vida que un mero cambio en el modo de producción. ${ }^{32}$ La vida fuera del capitalismo nos resulta impensable. Otras maneras de existir nos parecen ajenas, extrañas e incluso aterradoras. Como también señalara Gramsci, toda alternativa a la civilización que conocemos la identificamos inmediatamente como bárbara y desordenada. ${ }^{33}$

El carácter negativo del hombre destructivo puede parecer desconcertante para aquellos que crean posible una política de transformación social a la que le baste con un programa político y pueda librarse por consiguiente de toda filosofía. Pues si bien esta actitud despreocupada más allá del gesto crítico puede parecer imprudente en lo político, es imprescindible

29. Benjamin, W.: «El carácter destructivo», en Discursos Interrumpidos I, Buenos Aires: Taurus, 1989, p. 159.

30. Ibidem.

31. Ibidem, p. 160.

32. Žižek, S.: «El espectro de la ideología», en Žižek, S. (comp.): Ideología. Un mapa de la cuestión. Buenos Aires: F.C.E., 2004, p. 7.

33. Gramsci, A.: «Tres principios, tres órdenes», en Antología, Madrid: Siglo XXI, 1977, p. 18.

Thémata. Revista de Filosofía N55 (2017) pp.: 267-286. 
en toda concepción filosófica de la política, que por naturaleza no puede ser otra cosa que crítica.

Ahora bien, el bárbaro no se recluye en lo negativo unilateral. Precisamente por su radicalismo, que trasciende todo protagonismo del Yo, por carecer de proyecto personal o de "programas» predefinidos, el destructor se inserta en la colectividad: «Así como el que crea, busca para sí la soledad, tiene que rodearse constantemente el que destruye de gentes que atestigüen su eficiencia.» ${ }^{34}$

¿Cómo se entiende esto, si a continuación agrega Benjamin que este carácter destructivo "está por todos lados expuesto a las habladurías» ${ }^{35}$ Benjamin dice que el carácter destructivo no tiene sentido en la soledad, sino en el contacto con la colectividad. Ahora bien, el carácter destructivo es también crítico de esa colectividad, especialmente en el aspecto que la colectividad muestra de "existencia inauténtica» que Benjamin identifica con el reino del chismorreo. Precisamente en esta contradicción con el hablar fácil, con el chismorreo cotidiano, con el reino de la eficacia, Benjamin dice que el destructor no hace esfuerzos por hacerse entender y lo identifica como un provocador del sentido común.

Sami Khatib, en su artículo donde examina el concepto positivo de barbarie en Benjamin, vincula este carácter destructor con una búsqueda de simplificación de la vida, dentro de un marco burgués donde existe un exceso de racionalización y de ficcionalización, una proliferación excesiva de relatos y de opiniones cotidianas:

Benjamin caracteriza al bárbaro como un simplificador anti-ideológico de la vida, que puede encarar las necesidades básicas de la humanidad en vez de complicarlas indefinidamente desde el punto de vista de la razón burguesa.... ${ }^{36}$

Khatib remite al ensayo de Benjamin «Experiencia y pobreza». Benjamin comienza ese texto hablando de una depreciación de la experiencia tras la Primera Guerra Mundial: los veteranos del conflicto volvieron mudos; «una generación que fue al colegio todavía en tranvía de caballos» ${ }^{37}$ había sido arrojada a campos de batalla dominados por obuses y ametralladoras. El trauma generacional de la guerra industrializada sería el caso

34. Benjamin, W.: «El carácter destructivo», O. Cit., p. 160.

35. Ibídem.

36. «Benjamin characterizes the barbarian as an anti-ideological simplifier of life who can meet humanity's basic needs rather than endlessly complicating them from the standpoint of bourgeois reason...» (Khatib, S.: O. Cit., la traducción es mía).

37. Benjamin, W.: «Experiencia y pobreza», en Obras Completas, Libro II/vol. 1, Madrid: Abada, 2007, p. 217.

Thémata. Revista de Filosofía $\mathrm{N}^{\circ} 55$ (2017) pp.: 267-286. 
extremo de lo que constituye un rasgo de nuestra época: «una miseria completamente nueva cayó sobre los hombres con el despliegue formidable de la técnica». ${ }^{38} \mathrm{Y}$ paralelamente a esta pobreza, tenemos una riqueza de ideas (o diríamos, de opiniones), con la «reanimación de la astrología y el yoga, de la christian science y la quiromancia, del vegetarianismo y de la gnosis, de la escolástica y el espiritismo». ${ }^{39}$ Benjamin llama al lector a confesar esta pobreza de su tiempo, donde proliferan opiniones y cosmovisiones arcaicas, en lo que constituye una «nueva barbarie». ${ }^{40}$

A partir de este estado de cosas, de silencio por una parte y por otra la nueva pobreza de la cháchara insustancial, Benjamin propone «introducir un concepto nuevo de barbarie, positivo»:41

¿Adónde lleva al bárbaro esa su pobreza de experiencia? A comenzar de nuevo y desde el principio, a tener que arreglárselas con poco, a construir con poco y mirando siempre hacia delante. ${ }^{42}$

Por eso Benjamin elogia a los artesanos de la escuela Bauhaus: el vidio y el acero vienen a traer una nueva pobreza, una limpieza barbárica que se opone al instinto de conservación del burgués, el cual, volcado al interior doméstico, llena sus estancias de bibelots y chucherías que son las huellas de su paso por el mundo.

Cuando Khatib recurre al texto sobre «El carácter destructivo», y recuerda que para Benjamin es la Naturaleza la que marca al destructor su tempo, propone interpretar aquí por naturaleza no el reino natural ajeno a la sociedad, sino el desarrollo tecnológico que se presenta como «segunda naturaleza», un término usado por el propio Benjamin en «La obra de arte...» en el contexto de su propuesta de "tecnología emancipadora». ${ }^{43}$

En La obra de arte en la época de su reproductibilidad técnica, Benjamin escribe acerca de la pérdida del "aura» que era el elemento central, casi sacro, de la obra de arte tradicional. ${ }^{44}$ Gracias al desarrollo de la técnica y a las herramientas de reproducción, y a partir de la masificación de la experiencia, el aura queda arrollada: «la técnica de la reproducción

\author{
38. Ibídem. \\ 39. Ibidem, p. 218. \\ 40. Ibídem. \\ 41. Ibidem. \\ 42. Ibidem. \\ 43. Khatib, S.: O. Cit. \\ 44. Benjamin, W.: «La obra de arte en la época de su reproductibilidad técnica», en Obras \\ Completas, Libro I/vol 2, Madrid: Abada, 2008, p. 55.
}

Thémata. Revista de Filosofía $\mathrm{N}^{\circ} 55$ (2017) pp.: 267-286. 
(...) desgaja al tiempo lo reproducido respecto al ámbito de la tradición». ${ }^{45}$ Es lo que sucede con el cine, un arte que se fundamenta en el desarrollo tecnológico y que solo es viable por la irrupción del número en la economía cultural: su «significado social (...) no resulta por cierto concebible sin incluir su aspecto destructivo, catártico: la liquidación del valor de la tradición dentro de la herencia cultural». ${ }^{46}$

El carácter destructivo benjaminiano nace de esta eclosión de la imaginación, de la representación ideológica y de la riqueza de opiniones particulares, que corren parejas a un empobrecimiento de la tradición. Ante esta eclosión, nace una añoranza «bárbara»:

Pobreza de experiencia: esto no hay que entenderlo en el sentido de que la gente desee una experiencia nueva. No, bien al contrario: quieren librarse de las experiencias, desean un entorno en el que puedan manifestar sin más, pura y claramente, su pobreza (exterior e interior), es decir, que surja algo decente. No son siempre ignorantes o inexpertos y a menudo se puede decir lo contrario: ellos han «devorado» todo eso, «la cultura»y, con ella, el "ser humano», y están ahítos y cansados. ${ }^{47}$

Sami Khatib no interpreta el texto "Experiencia y pobreza» como una idealización de la segunda, sino más bien como una utilización de la misma como medio para la liberación de la opresiva proliferación de las opiniones ${ }^{48}$ y de la jerga de la complejidad, nuestra doxa contemporánea. Si el paradigma post-industrial se define, según autores como Berardi, por la creatividad del trabajo cognitivo ${ }^{49}$ Khatib recurre al bárbaro benjaminiano para sustraer su función ideológica, «deshaciendo la competición pluralista de los puntos de vista particulares en el mercado de opiniones.. ${ }^{50}$

Žižek escribe que la Aufhebung de Hegel se caracteriza realmente como una reducción: aquello que es superado resulta conservado, pero en una forma "abreviada" que aleja al objeto de su contexto en el mundo-dela-vida constitutivo de su horizonte inmediato. ${ }^{51}$ Para Hegel, según Žižek, la dialéctica no pretendería la superación de los fenómenos particulares,

\section{Ibídem.}

46. Ibídem.

47. Benjamin, W.: «Experiencia y pobreza», O. Cit., p. 221.

48. Khatib, S.: O. Cit.

49. Berardi, F.: «Del intelectual orgánico a la formación del cognitariado», en Archipiélago, 66, 2005, pp. 57-67.

50. «undoing the pluralistic competition of privately owned standpoints on the marketplace of opinions» (Khatib, S.: O. Cit., la traducción es mía).

51. Žižek, S.: «Preface to the New Edition: The Idea's Constipation?», en The sublime object of ideology, New York: Verso, 2008, pp. viii-xi.

Thémata. Revista de Filosofía ${ }^{\circ} 55$ (2017) pp.: 267-286. 
conectándolos entre ellos para integrarlos en una totalidad, en una visión de conjunto. El problema reside en cómo superar la propia conciencia espontánea, que tiende a ver demasiadas de estas conexiones, perdiéndose en el detalle: "...cuando observamos una cosa, vemos demasiado en ella, caemos bajo el hechizo de la riqueza del detalle empírico, que nos evita percibir claramente la determinación conceptual». ${ }^{52}$

Esta manera de entender la reducción hegeliana sería análoga a la propuesta que hace Benjamin. La barbarie en el mal sentido está del lado de los mistificadores, de los propositivos, de quienes ante la crisis de la experiencia se "arremangan» y se lanzan a proponer alternativas y modos nuevos de sabiduría. La barbarie en un sentido positivo crea algo nuevo a partir de lo mínimo, a partir de lo colectivo, y desde la renuncia voluntaria al rico mundo de la experiencia que se divisa como perdido para siempre en los albores de una nueva crisis mundial:

La crisis económica está a las puertas y tras ella, como una sombra, la guerra inminente. Aguantar es hoy cosa de unos pocos poderosos que, Dios lo sabe, son menos humanos que muchos; en el mayor de los casos son más bárbaros, pero no de la manera buena. Los demás en cambio tienen que arreglárselas partiendo de cero y con muy poco. Lo hacen a una con los hombres que desde el fondo consideran lo nuevo como cosa suya y lo fundamentan en atisbos y renuncia..$^{53}$

La obra de Robert E. Howard se gestó en el mismo periodo de crisis; mientras Benjamin escribe estas líneas, Howard está publicando sus artículos en revistas pulp de los años 30, luchando por sobrevivir económicamente con los exiguos cheques que, con retraso, le hacía llegar el editor. En ese marco, surgiendo de un contexto de barbarismo, Howard tuvo la inteligencia de presentar al bárbaro como negación de los tiempos y crítico de su propio contexto social.

Las revistas pulp supusieron una revolución en la comunicación. Hicieron posible la divulgación de la obra de autores «menores» (como Robert E. Howard o Lovecraft en Weird Tales, o Hammet en Black Mask), que revolucionaron nuestra concepción del mundo moderno a través de la cultura popular. Multiplicando el número de los autores, prosiguieron la revolución inaugurada por la prensa y anticiparon la eclosión democratizadora en la era de la comunicación digital, donde cualquiera puede escribir y la selección a través de editoriales, comités de redacción o jefes

52. «...when we observe a thing, we see too much in it, we fall under the spell of the wealth of empirical detail which prevents us from clearly perceiving the notional determination» (Ibidem, p. xi, la traducción es mía).

53. Benjamin, W.: «Experiencia y pobreza», O. Cit., p. 173.

Thémata. Revista de Filosofía ํ55 (2017) pp.: 267-286. 
de prensa ya no excluye ver difundida la obra por otros medios que pueden garantizar el acceso, a través de la red, de un público potencialmente infinito. Esto significa la pérdida de capacidad censora por parte del experto, y la práctica igualdad de condiciones (con efectos materiales importantísimos), para el gran público no experto, entre lo contrastado y la mera doxa.

Esta proliferación no puede ser celebrada acríticamente, pero tampoco ignorada como un elemento de «enriquecimiento empobrecedor» de la cultura contemporánea. Si queremos recuperar el papel de la ciencia como crítica, muy limitado en estos tiempos de mercantilización y burocratización de la investigación y de la universidad, debemos tomarnos en serio esta proliferación sin filtro previo que facilitan las nuevas tecnologías. ¿Y no era eso lo que descubrieron Marx y Engels, cuando enfocaron algunas de sus obras más famosas desde el punto de vista de la crítica a los ideólogos célebres del momento, en la época del periódico, la novela por entregas y el folleto como medio de difusión de masas ${ }^{54}$ Lo que Marx y Engels practicaron por medio de esta crítica, que no era sino una depuración y simplificación de las «complejas» interpretaciones de la realidad social de su época, puede decirse que a otra escala también lo hizo Howard de manera literaria: proponer una simplificación de la experiencia, que no es pusilánime ni meramente evasiva, sino radical y comprometida.

\section{Barbarie y violencia divina}

Robert E. Howard era un escritor profesional, que debía especiar sus relatos con los picantes del erotismo y la violencia, al objeto de que fueran publicables en revistas pulp. No obstante, la violencia no es solo un recurso sensacionalista, sino también una experiencia explorada con un sentido artístico y filosófico; queremos analizar ahora el sentido profundo en el cual la violencia es un instrumento del bárbaro.

Comparado con los relatos de Howard, la violencia está mal representada en Tolkien. Escenas de batallas como las que proliferan en los filmes de Peter Jackson, y que en Tolkien se hallan ausentes, deben más a Robert E. Howard, que supo trasladar la tensión de un choque armado con toda claridad y detalle. ${ }^{55}$ Por dar un único ejemplo extremo, la batalla final de $E l$ Hobbit no es narrada por Tolkien: Bilbo cae inconsciente en el primer choque y, cuando recobra el conocimiento, asistimos al relato que le ofrecen

54. Obras como La sagrada familia, La ideología alemana o El anti-Dühring, eran textos de situación donde Marx y Engels ajustaban cuentas con la filosofía y con la cultura de su época (Dühring, los hegelianos, o incluso novelistas como Eugène Sue).

55. Herron, D.: «Introduction», en The barbaric Triumph, O. Cit., p. xiv.

Thémata. Revista de Filosofía N55 (2017) pp.: 267-286. 
a posteriori de los hechos ${ }^{56} \mathrm{Nada}$ tiene que ver con la perspectiva más realista de Howard, donde precisamente pierde fuerza el relato «político» del contexto, frente a la experiencia concreta del guerrero individual. La batalla en «El Coloso Negro», a diferencia de la batalla en El Hobbit de Tolkien, es narrada con claridad y tensión. La batalla no tiene un auténtico propósito, un noble fin, más allá de la voluntad por parte de Conan de vender caro el propio pellejo: "his one thought was the wild beast instinct of slay before he died» ${ }^{57}$ relata el narrador. Tanto es así, que el relato de Howard no concluye con la victoria militar. Cuando las tropas de Conan van ganando, éste se separa para perseguir al hechicero que secuestra a la mujer, y el relato concluye con el duelo y con la conquista amorosa de la misma. Así las cosas, ¿no cabría decir que en la lucha del bien contra el mal, en Tolkien, hay más implicación belicista (por causas políticas: debe aniquilarse a un oscuro Enemigo) que en Conan, donde la vida guerrera no se justifica por ninguna gesta heroica sino por la necesidad de supervivencia?

Naturalmente, sería una difamación calificar de belicista a Tolkien, que experimentó directamente el horror de la Gran Guerra y que, como diversos críticos han señalado, ${ }^{58}$ probablemente trasladó a su obra mucho de aquella experiencia. Pero junto con elementos que pondrían el relato a la altura de grandes obras antibelicistas inspiradas en aquel conflicto, también trasladó Tolkien el maniqueísmo de quienes, como la gran mayoría de la población europea en 1914, se sienten comprometidos con los intereses de su nación. Solo en este sentido, y como hemos dicho de forma contradictoria, Tolkien parece legitimar la idea de la "guerra justa", y presenta como decadentes las culturas (como las élficas) que, traumatizadas por una larga historia de enfrentamientos con Sauron, son reticentes a implicarse directamente en el conflicto.

Así las cosas, ¿existe un modo de subvertir la idea de violencia como, en palabras de Clausewitz, un conflicto entre voluntades tendente al extremo? ${ }^{59}$ En «Hacia la crítica de la violencia», Walter Benjamin elabora la distinción entre violencia mítica y violencia divina partiendo del concepto de «huelga general revolucionaria» de Georges Sorel. En Reflexiones sobre la violencia, Sorel distingue la huelga general revolucionaria de la simple huelga general política. ${ }^{60}$ En esta, el Estado simplemente cambiaría de manos, sin perder su poder; en cambio, la huelga general revolu-

56. Tolkien, J.R.R.: O. Cit., p. 214.

57. Howard, R. E.: «Black Colossus», O. Cit., p. 180.

58. Garth, J.: Tolkien y la Gran Guerra. El origen de la tierra media, Barcelona: Minotauro, 2014.

59. Clausewitz, C. V.: De la guerra, Madrid: La esfera de los libros, 2005, pp. 17-18.

60. Sorel, G.: Reflexiones sobre la violencia, Madrid: Alianza, 2005.

Thémata. Revista de Filosofía $\mathrm{N}^{\circ} 55$ (2017) pp.: 267-286. 
cionaria tiene como fin inmediato la supresión del propio Estado. En la interpretación de Benjamin, lo realmente violento es la huelga política, cuya forma de coacción «causa solamente una exterior modificación de las condiciones del trabajo», ${ }^{61}$ para lo cual ejerce métodos extorsivos (paros, piquetes, etc...) pero no tiene por objeto sin embargo el marco general de las relaciones capitalistas de producción y por consiguiente la violencia estructural de las sociedades bajo el modo de producción capitalista. La huelga general revolucionaria, en cambio, no busca meros beneficios económicos o corporativistas: los trabajadores abandonan su puesto «con la decisión de reanudar un trabajo completamente transformado; uno no forzado por el Estado (un cambio radical que este tipo de huelga no provoca, sino que solo consuma)». ${ }^{62}$ En definitiva, la huelga general revolucionaria resiste a su institucionalización, impugna el sistema en lugar de reformarlo a través de reformas económicas o jurídicas, lo cual legitimaría el estado de derecho vigente. Pero por este mismo motivo, naturalmente, para el Estado y el gobierno la huelga revolucionaria es concebida como la forma más violenta de huelga. Esto es así porque niega la propia forma Estado y el propio orden jurídico, ${ }^{63}$ pese a que la huelga general soreliana se presenta como un procedimiento que limita el empleo de la violencia en el transcurso de un proceso revolucionario. ${ }^{64}$

Walter Benjamin recurre a la distinción entre huelga política y huelga general revolucionaria para trazar su propia diferenciación entre dos modos de violencia: la violencia mítica, como institución o reproducción de la norma jurídica (y establecimiento de un castigo correspondiente al infractor) y la violencia divina, como supresión del derecho y por tanto del poder del Estado, autorizado normativamente por el círculo freudiano de represión-agresión-culpa.

La violencia se aparecería siempre en Robert E. Howard con este doble cariz. Hay una violencia civilizada que instituye las normas, que establece y restablece el poder del Estado. Es la violencia de Conan autocoronándose como rey de Aquilonia, gobernando de manera justa y reforzando a la nación tras el periodo anterior de crisis y decadencia. Pero también hay una violencia disolvente, divina, cada vez que el monarca deconstruye la propia institución monárquica, cada vez que se reafirma como un bárbaro

61. Benjamin, W.: «Hacia la crítica de la violencia», en Obras, Libro II/vol. 1, O. Cit., p. 197.

62. Ibídem.

63. Ibidem, p. 198.

64. Ibídem.

Thémata. Revista de Filosofía $\mathrm{N}^{\circ} 55$ (2017) pp.: 267-286. 
que circunstancialmente ocupa el lugar de un rey (provocando de este modo la indignación de las familias nobles, conservadoras y tradicionalistas).

Asimismo, este reconocimiento por parte de un rey de que el poder es una carga, y que debe despojarse de sus elementos simbólicos e ideológicos (es obligado el paralelismo con el Frodo de Tolkien, que arroja el anillo de poder al fuego en lugar de conservarlo), constituye el núcleo elemental de cualquier política transformadora. La presencia del bárbaro en el trono significa que cualquier ciudadano anónimo puede gobernar, a condición de que no se crea respaldado por ninguna autoridad simbólica. Este gobierno de cualquiera es fundamental para entender la democracia en toda su radicalidad.

\section{Referencias bibliográficas}

a. De Robert E. Howard:

Howard, R.E.: «Black Colossus», en The Coming of Conan the Cimmerian. New York: Del Rey, 2003, pp. 152-184. : «By this axe I rule!», en The best of Robert E. Howard, vol. 2. New York: Del Rey, 2007, pp. 1-17. : «Queen of the Black Coast», en The Coming of Conan the Cimmerian, O. Cit., pp. 119-149. : "The Phoenix on the Sword», en The Coming of Conan the Cimmerian, O. Cit., pp. 5-27.

b. Otros:

Althusser, L.: «Remarque sur une catégorie: "Procés sans Sujet ni Fin(s)"», en Réponse a John Lewis. Paris: Maspero, 1973, pp. 69-76.

Benjamin, W.: «El carácter destructivo», en Discursos Interrumpidos I. Buenos Aires: Taurus, 1989, pp. 108-161.

: «Experiencia y pobreza», en Obras, Libro II/vol. 1. Madrid: Abada, 2007, p. 216-222.

: "Hacia la crítica de la violencia», en Obras, Libro II/ vol. 1, O. Cit., pp. 183-206.

: «La obra de arte en la época de su reproductibilidad técnica", en Obras Completas, Libro I/vol. 2. Madrid: Abada, 2008, pp. 49-85. Libro I/vol. 2, O. Cit., pp. 303-318.

: "Sobre el concepto de historia», en Obras Completas,

Berardi, F.: «Del intelectual orgánico a la formación del cognitariado», en Archipiélago 66, 2005, pp. 57-67. 
Clausewitz, C.V.: De la guerra. Madrid: La esfera de los libros, 2005. Dolar, M.: «Beyond interpellation», Qui Parle, 6:2, 1993, pp. 75-96.

Garth, J.: Tolkien y la Gran Guerra. El origen de la tierra media. Barcelona: Minotauro, 2014.

Gramsci, Antonio: «Tres principios, tres órdenes», en Antología. Madrid: Siglo XXI, 1977, pp. 17-23. 2004 .

Herron, D. (ed.): The barbaric Triumph, Rockville: Wildside Press,

Hoffman, Ch.: «Conan The Existential», en Herron, D. (ed): The barbaric Triumph, O. Cit., pp. 5-10.

Khatib, S.: "A Positive Concept of Barbarism. Benjamin and Consequences», charla dentro del ciclo "Constellations of Contemporary Thought» en el Multimedia institute klub MaMa, Zagreb, Croatia, 27 de febrero de 2015, https://www.youtube.com/watch?v=VGQxP5r9htQ [Consultado: 3/07/2016].

Lévi-Strauss, C.: «El hechicero y su magia», en Antropología estructural. Barcelona: Paidós, 1987, pp. 195-210.

Martí, J.: «Los cuatro elementos. Fundamentos conceptuales introductorios para el estudio de la religión», en VV.AA.: Antropología de la religión. Barcelona: UOC, 2003,

Marx, K.: «Tesis sobre Feuerbach», en K. Marx y F. Engels, Obras Escogidas, 2. Madrid: Akal, 1975, pp. 426-428.

: "Carta a Vera Zassulitch, 8 de marzo de 1881», en Marx, K. y Engels, F.: Cartas sobre El Capital. Barcelona: Laia, 1974, pp 234-235.

Marx, K. y Engels, F.: "Manifiesto del Partido Comunista», en Obras Escogidas, 1. Madrid: Akal, 1975, pp. 11-55.

Nietzsche, F.: El nihilismo: escritos póstumos. Barcelona: Península, 2002.

Sorel, G.: Reflexiones sobre la violencia. Madrid: Alianza, 2005.

Slotkin, R.: Regeneration through violence. The Mythology of the American Frontier, 1600-1860. Norman: University of Oklahoma Press, 2000. Tor, 2002.

Sprague de Camp, L. y Carter, L.: Conan the Liberator. New York:

Tolkien, J.R.R.: El hobbit. Barcelona: Círculo de Lectores, 1988.

Trout, S.R.: «Heritage of Steel: Howard and the Frontier Myth», en Herron. D. (Ed): The barbaric Triumph, O. Cit., pp. 59-78.

Žižek, S.: "El espectro de la ideología», en Žižek, S. (comp.): Ideología. Un mapa de la cuestión. Buenos Aires: F.C.E., 2004, pp. 7-42. : The sublime object of ideology. New York: Verso, 2008. 